\section{Commentary: Bronchial artery aneurysms: Embolization or bust?}

Ernest G. Chan, MD, MPH, and

Matthew J. Schuchert, MD

When a patient presents with active chest pain, proper workup should be performed immediately because its etiology can be life threatening. When chest pain persists after early medical therapy, conditions such as aortic dissection and myocardial infarction should remain high in the differential diagnosis and require timely intervention. Detailed radiographic investigations are required, because they will often dictate the proper intervention required for definitive therapy. Ishida and colleagues ${ }^{1}$ have reported the unusual presentation of a bronchial artery aneurysm (BAA) presenting with chest pain. Their report highlights the need for sound clinical judgment and the importance of detailed radiographic imaging to arrive at an expeditious diagnosis. Given the close proximity of the bronchial artery to the aortic arch, computed tomography imaging alone was not able to definitively rule out aortic pathology. Because the clinical presentation of the patient did not correlate with the usual diagnoses, Ishida and colleagues ${ }^{1}$ used magnetic resonance imaging to help identify an intact aortic adventitial plane abutting the BAA.

BAA is a rare, but potentially deadly, disorder occurring in less than $1 \%$ of all aneurysms identified on selective bronchial arteriography. ${ }^{2}$ As such, a recent review of the reported data identified only 63 cases reported in 56 studies over a span from 1977 to $2014 .{ }^{3}$ Of these cases, 46 patients had undergone transcatheter arterial embolization. Within this treatment cohort, 5 embolization procedures failed

\footnotetext{
From the Department of Cardiothoracic Surgery, University of Pittsburgh School of Medicine and University of Pittsburgh Medical Center, Pittsburgh, Pa.

Disclosures: The authors reported no conflicts of interest.

The Journal policy requires editors and reviewers to disclose conflicts of interest and to decline handling or reviewing manuscripts for which they may have a conflict of interest. The editors and reviewers of this article have no conflicts of interest.

Received for publication June 19, 2020; revisions received June 19, 2020; accepted for publication June 27, 2020; available ahead of print June 30, 2020.

Address for reprints: Matthew J. Schuchert, MD, Department of Cardiothoracic Surgery, University of Pittsburgh Medical Center, 1400 Locust St, Building D, Suite 5121, Pittsburgh, PA 15219 (E-mail: schuchertmj@upmc.edu).

JTCVS Techniques 2020;3:57-8

2666-2507

Copyright (C) 2020 The Authors. Published by Elsevier Inc. on behalf of The American Association for Thoracic Surgery. This is an open access article under the CC BY-NCND license (http://creativecommons.org/licenses/by-nc-nd/4.0/).

https://doi.org/10.1016/j.xjtc.2020.06.041
}

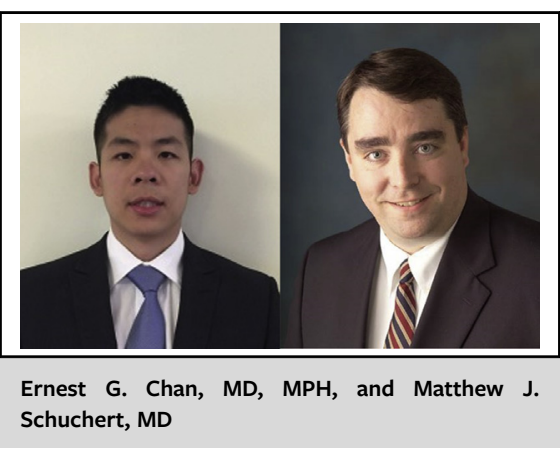

\author{
CENTRAL MESSAGE \\ Through the use of excellent \\ clinical judgment and radio- \\ graphic investigation, bronchial \\ artery aneurysms can be treated \\ effectively with endovascular \\ embolization.
}

immediately and had required either an additional embolization procedure or surgical intervention. An additional 5 patients had experienced BAA recurrence found on follow-up imaging studies, which had been anecdotally associated with the size of the aneurysm and the presence of collateral arteries. Several additional reports had described the use of endovascular stents in the setting of rupture and the constraints associated with the anatomic location of the BAA. ${ }^{3-6}$

Although the true incidence of rupture is unknown, one of the largest reported reviews documented a rupture rate of $35 \%$ in mediastinally located BAAs. Therefore, the use of transcatheter aneurysm embolization in a timely fashion is required. Although this first treatment had failed in $21.7 \%$ of patients with BAAs, because of the low morbidity associated with transcatheter procedures, we believe it is a viable and safe first option. ${ }^{7-9}$ Careful evaluation of the diseased anatomy is required to ensure the defect in its entirety has been identified to maximize the procedure's success. Several important characteristics to note include the size and location of the BAA and the evidence of collaterals. Because of the structures surrounding the bronchial artery, additional radiographic studies such as magnetic resonance imaging could be needed. Ultimately, because of the rarity of BAAs, no formal consensus has been reached regarding the treatment algorithm and the long-term outcomes have not been well defined. Nevertheless, we congratulate Ishida and colleagues ${ }^{1}$ for a detailed report of their experience with treating BBAs with an endovascular approach. 


\section{References}

1. Ishida S, Koike K, Fujita T, Yagami K. Bronchial artery aneurysm mimicking aortic arch aneurysm or aortic dissection. J Thorac Cardiovasc Surg Tech. 2020; 3:54-6.

2. Fujita J, Akashi K, Kunikane H, Nakajima I, Saito S, Abe S, et al. A case of bronchial artery aneurysm demonstrating a mass shadow on chest X-ray film. Nihon Kyobu Shikkan Gakkai Zasshi. 1991;29:1591-5.

3. Di X, Ji DH, Chen Y, Liu CW, Liu B, Yang J. Endovascular treatment of ectopic bronchial artery aneurysm with brachiocephalic artery stent placement and coil embolization: a case report and literature review. Medicine (Baltimore). 2016;95:e4461.

4. Date Y, Fujii T, Fuke M, Terasaki T, Sakaguchi M, Fukui D, et al. Successful treatment with aortic stent graft and transcatheter embolization for bronchial artery aneurysm. Kyobu Geka. 2018;71:1004-7.

5. Fiorucci B, Simonte G. Treatment of a bronchial artery aneurysm with placement of an aortic thoracic stent-graft. Eur J Vasc Endovasc Surg. 2016;51:717.
6. Xu Z, Kong Y, Hu C, Huang S, Tan Y. Ruptured bronchial artery aneurysm treated with aortic stent graft and aneurysm embolization. Curr Med Imaging Rev. 2019; 15:74-7.

7. Wang W, Chang H, Liu B, Wang W, Yu Z, Chen C, et al. Long-term outcomes of elective transcatheter dense coil embolization for splenic artery aneurysms: a two-center experience. J Int Med Res. 2019;48. 0300060519873256.

8. Patel A, Weintraub JL, Nowakowski FS, Kim E, Fischman AM, Ellozy SH, et al. Single-center experience with elective transcatheter coil embolization of splenic artery aneurysms: technique and midterm follow-up. J Vasc Interv Radiol. 2012; 23:893-9.

9. Ikoma A, Nakai M, Loffroy R, Midulla M, Kamisako A, Higashino N, et al. Transcatheter arterial embolization of a splenic artery aneurysm with N-butyl cyanoacrylate/Lipiodol/ethanol mixture with coil-assisted sandwich technique. Quant Imaging Med Surg. 2019;9:346-9. 